\title{
Phenotypic differences between microvascular and macrovascular smooth muscle cells and their contribution to coronary microvascular dysfunction
}

\author{
Kirsten Riches-Suman \\ School of Chemistry and Biosciences, University of Bradford, Bradford BD7 1DP, UK. \\ Correspondence to: Dr. Kirsten Riches-Suman, School of Chemistry and Biosciences, University of Bradford, Richmond Road, \\ Bradford BD7 1DP, UK. E-mail: k.riches@bradford.ac.uk
}

How to cite this article: Riches-Suman K. Phenotypic differences between microvascular and macrovascular smooth muscle cells and their contribution to coronary microvascular dysfunction. Vessel Plus 2021;5:28. https://dx.doi.org/10.20517/25741209.2021 .45

Received: 15 Mar 2021 First Revised: 8 Apr 2021 Revised: 15 Apr 2021 Accepted: 7 May 2021 Published: 11 Jun 2021

Academic Editor: Gaetano Antonio Lanza Copy Editor: Xi-Jun Chen Production Editor: Xi-Jun Chen

\begin{abstract}
Coronary microvascular dysfunction (CMD) is an under-diagnosed condition characterized by functional alteration of the small coronary arterioles and the cardiac capillary bed. The vessels do not dilate appropriately in response to changes in cardiac oxygen demand, leading to chest pain and symptoms of angina. These blood vessels contain two major cell types: the endothelial cells, which line the blood vessels and detect changes in oxygen demand, and smooth muscle cells (SMC) which respond to these changes by contracting or relaxing to provide an optimal blood supply to the cardiac tissue. Many CMD studies have focused on the endothelial cells as these cells secrete vasorelaxants and vasoconstrictors. However, comparably fewer studies have examined SMC despite their functional role in contracting and relaxing. A variety of health conditions and lifestyle choices, such as diabetes, hypertension and cigarette smoking, can promote the development of both CMD and macrovascular coronary artery disease; a condition where SMC have been studied extensively. This review article will consider the influence of CMD on SMC phenotype. It will discuss the structural, cellular and molecular changes in CMD, and will summarise how co-morbidities can have differing effects on micro- and macro-vascular SMC phenotype and function, which complicates the development of new therapeutic avenues for CMD.
\end{abstract}

Keywords: Smooth muscle cell, coronary microvascular dysfunction, atherosclerosis, phenotype, contraction, proliferation, differentiation 


\section{INTRODUCTION}

Coronary microvascular dysfunction (CMD) manifests as functional decline of the arterioles and smaller vessels that supply the myocardium with blood. It is distinct from macrovascular atherosclerotic lesions that affect the coronary arteries [coronary artery disease (CAD)], although the two conditions are often present at the same time and can coexist on the same patient ${ }^{[1,2]}$. Indeed, $>30 \%$ of patients with CAD who have undergone percutaneous coronary intervention still present with angina post-surgery, which can be attributed to underlying $\mathrm{CMD}^{[3,4]}$. CMD is characterized by impaired coronary microvascular dilation resulting in insufficient blood, oxygen and nutrients reaching the cardiac tissue ${ }^{[2]}$ and can ultimately lead to heart failure with preserved ejection fraction $(\mathrm{HFpEF})^{[5]}$. CMD is much more difficult to diagnose than $\mathrm{CAD}$ as the symptoms of angina, fatigue and breathlessness can be caused by any number of different conditions, and definitive coronary provocative tests are not routinely conducted ${ }^{\left[{ }^{[6]}\right.}$.

Conditions such as diabetes, hypertension and lifestyle choices (e.g., smoking) are known to predispose towards the development of $\mathrm{CMD}^{[5]}$. These risk factors also predispose individuals to $\mathrm{CAD}$ and atherosclerotic progression, so it is perhaps unsurprising that both macro- and micro-vascular coronary diseases often go hand-in-hand. However, epidemiological studies have revealed that CMD and HFpEF are more common in women, which are in direct contrast to population studies of CAD, where male gender is prevalent ${ }^{[5,7]}$. Thus, it is likely that the underlying cellular and molecular mechanisms leading to CAD and $\mathrm{CMD}$, whilst having similar risk factors, are distinct from one another.

\section{Coronary vasculature}

Like all tissues in the body, the heart needs a robust blood supply to provide the oxygen and nutrients it needs to keep functioning. Myocardial tissue is perfused by a number of coronary arteries such as the right coronary, left main coronary, left anterior descending and left circumflex arteries. Coronary arteries have a typical diameter of 3-4 $\mathrm{mm}^{[8]}$ and they are conductance vessels; their tone maintained by endothelial cell sensing and shear stress. They possess a thick muscular wall comprised of multiple layers of smooth muscle cells (SMC) and an adventitial outer layer [Figure 1]. These arteries feed pre-arterioles (100-400 $\mu \mathrm{m}$ in diameter) and arterioles (40-100 $\mu \mathrm{m}$ in diameter) which are resistance vessels and eventually give rise to the dense cardiac capillary bed. The tone of these microvascular arterioles is regulated principally by intralumenal pressure sensing by $\mathrm{SMC}^{[9]}[$ Figure 1].

Whilst coronary microvessels possess a functional SMC layer, smaller microvessels/capillaries recruit pericytes instead of SMC. Pericytes and SMC share the same embryological precursors but differ in their functionality and expression patterns. Pericytes express chemoattractants and help to stabilize endothelial tubes to support blood vessel development, whereas SMC express contractile markers and comprise mature vascular walls, without supporting endothelial tube formation ${ }^{[10]}$.

\section{Smooth muscle cells}

SMC are the principal cell type in the vascular wall, comprising much of the cellular content of the medial layer. They maintain vascular tone through controlled contraction and relaxation in response to factors secreted from endothelial cells. Under healthy conditions, they exist in a contractile, differentiated phenotype. They adopt a spindle morphology, possess extensive contractile machinery [including alpha smooth muscle actin ( $\alpha$-SMA) and stress fibres], ion channels and calcium signalling proteins, and have a very low turnover rate ${ }^{[1,1,2]}$.

In cases of disease (e.g., atherosclerosis) or injury (e.g., following revascularization surgery), SMC have an inherent ability to switch phenotype and dedifferentiate into a synthetic state. Here, the SMC loses its 


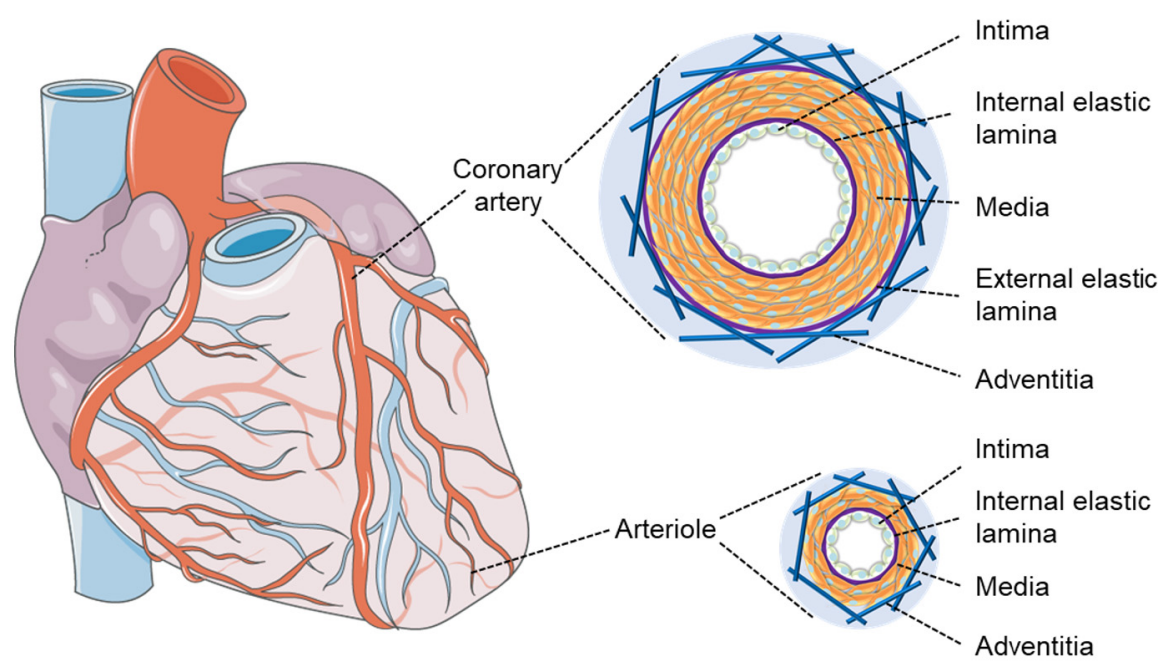

Figure 1. Structure of the coronary vasculature. Coronary arteries are comprised of an inner endothelial cell lining (intima), internal elastic lamina, multiple layers of smooth muscle cells (media), external elastic lamina and an outer adventitia comprised of fibroblasts and connective tissue. Coronary arteries branch into pre-arterioles and arterioles which are much smaller. Whilst they retain the triple layering (intima, media and adventitia) and internal elastic lamina, the external elastic lamina is lost and the medial and adventitial layers are much thinner.

spindle morphology and becomes more rhomboid in shape. The contractile machinery is down-regulated and the cytoskeleton becomes disordered; signalling molecule expression changes from those that favour contraction to those that favour proliferation and migration. This phenotypic switching can be transient and is fully reversible, allowing the SMC to dynamically respond according to physiological and environmental demand ${ }^{[1,12]}$. SMC can also dedifferentiate into osteogenic ${ }^{[13]}$ or macrophage-like phenotypes $^{[14]}$.

The phenotype of SMC possesses an extra level of complexity as it alters throughout the life course of an individual, and according to gender ${ }^{[15,16]}$. Relaxation, migration and ion channel responses decline with age, and SMC increasingly adopt a senescent and/or osteogenic phenotype and are no longer able to respond to signalling cues in the same way as younger $\mathrm{SMC}^{[17-20]}$, which contributes to the age-related increase in cardiovascular diseases. A very recent study has demonstrated that SMC from atherosclerotic lesions in females have a distinct gene regulatory signature and phenotype compared to males, which contributes to atherosclerotic plaque stabilization ${ }^{[19]}$. Furthermore, female mice experience mineralocorticoid-specific vascular stiffening at much later ages than their male counterparts ${ }^{[21]}$. These findings are just the tip of the iceberg; a comprehensive analysis of SMC phenotype throughout the lifespan of males and females would be fascinating and may open up new avenues for personalized medicine with respect to CMD or CAD.

Given that both macrovascular coronary arteries and microvascular coronary arterioles possess a functional medial layer of SMC [Figure 1], one might expect that they are phenotypically comparable. However, a complex relationship exists between macrovascular and microvascular SMC; whereby the behaviour and phenotype of one can have diverse effects on the behaviour and phenotype of the other ${ }^{[22]}$. This article will review evidence pertaining to differential phenotypes between SMC from the coronary arteries and the coronary microcirculation. It will then discuss how these phenotypes contribute to CMD and how common underlying conditions such as diabetes, hypertension or smoking affect macro- and micro-vascular SMC in different ways. 


\section{SMC PHENOTYPE IN MICRO- VS. MACRO-VESSELS}

Previous studies have highlighted phenotypic and behavioural differences in endothelial cells isolated from microvascular and macrovascular sources ${ }^{[23-25]}$. Furthermore, phenotypic differences have been observed between SMC from different macrovessels (internal mammary artery and saphenous vein) from the same patient ${ }^{[26]}$. Thus, it is entirely likely that SMC from the microcirculation will be phenotypically distinct from those from the macrocirculation.

Data regarding phenotypic differences between coronary microvascular and macrovascular SMC are remarkably scant. The few studies that have assessed this have focused on differences within the contractile phenotype. Human coronary arterial SMC are reportedly stiffer than their microvascular counterparts (elastic modulus $>7 \mathrm{kPa} v s .<4 \mathrm{kPa}$ ). However, these studies exploited differing experimental parameters and so cannot be definitively compared ${ }^{[27,28]}$. Nonetheless, given that arteries are conductance vessels and arterioles are resistance vessels, this is likely to be true. In addition to stiffness of both the cell and the extracellular matrix, SMC contractility is tightly interlinked with ionic flux (described in greater detail below). In a Yucatan swine model, spontaneous transient outwards $\mathrm{K}^{+}$currents were much more frequent in coronary microvascular SMC vs. macrovascular SMC ${ }^{[29]}$. These spontaneous $\mathrm{K}^{+}$currents have been associated with triggering vasorelaxation ${ }^{[30]}$ and these observations fit with the concept of microvascular tone being controlled through SMC pressure detection.

SMC phenotypic differences between macrovascular and microvascular beds represent an area that is greatly understudied. An examination of the contractile, proliferative and secretory ability of these cells in both settings would be valuable in assessing their influence on cardiovascular disease development, and may give insight into medication strategies that may be beneficial for CMD specifically, rather than cardiovascular disease as a whole.

\section{SMC PHENOTYPE IN CORONARY MICROVASCULAR DYSFUNCTION}

The principal feature of CMD is a failure of the cardiac microvasculature to respond appropriately to changes in myocardial oxygen demand. It can be caused by problems with vasodilation or by coronary microvascular spasm causing an acute reduction in blood flow ${ }^{[2]}$. To date, more emphasis has been given to researching how endothelial cells contribute to CMD, with comparably fewer studies conducted on SMC despite their crucial role in maintaining vascular tone.

\section{Vasoconstriction and vasorelaxation}

$\mathrm{Ca}^{2+}$ signalling is a major underlying cellular mechanism controlling SMC tone and contraction in the microvasculature. Activation of the $\mathrm{Na}^{2+} / \mathrm{K}^{+}$ATPase pump and inwardly rectifying potassium $\left(\mathrm{K}_{\mathrm{IR}}\right)$ channels ${ }^{[31]}$, and calcium-activated potassium $\left(\mathrm{K}_{\mathrm{Ca}}\right)$ channels ${ }^{[32]}$ induce membrane hyperpolarization and vasorelaxation. $\mathrm{K}_{\mathrm{Ca}}$ channels are a family of three different classes; small-conductance $\mathrm{Ca}^{2+}$-activated potassium channels $\left(\mathrm{SK}_{\mathrm{Ca}}\right)$, intermediate-conductance $\mathrm{Ca}^{2+}$-activated potassium channels $\left(\mathrm{IK}_{\mathrm{Ca}}\right)$, and largeconductance $\mathrm{Ca}^{2+}$-activated potassium channels $\left(\mathrm{BK}_{\mathrm{Ca}}\right)$, the latter being prevalent in SMC. Hence, understanding the ion channel landscape of these cells is imperative for understanding SMC function. This has recently been extensively reviewed ${ }^{[17]}$ and is summarized in Figure 2. It is clear that there is complex cross-talk between transient receptor potential (TRPC/TRPM) channels, voltage-gated calcium channels $\left(\mathrm{Ca}_{\mathrm{V}}\right), \mathrm{K}_{\mathrm{Ca}}$, voltage-gated potassium channels $\left(\mathrm{K}_{\mathrm{V}}\right)$, ATP-activated potassium channels $\left(\mathrm{K}_{\mathrm{ATP}}\right)$ and $\mathrm{K}_{\mathrm{IR}}$ channels to control intracellular $\mathrm{Ca}^{2+}$ levels and $\mathrm{K}^{+}$flux.

CMD is associated with a failure of the coronary microcirculation to relax appropriately in response to myocardial oxygen demand. Recently, Zhao et al. ${ }^{[33]}$ have demonstrated that cardiomyocyte ATP depletion 


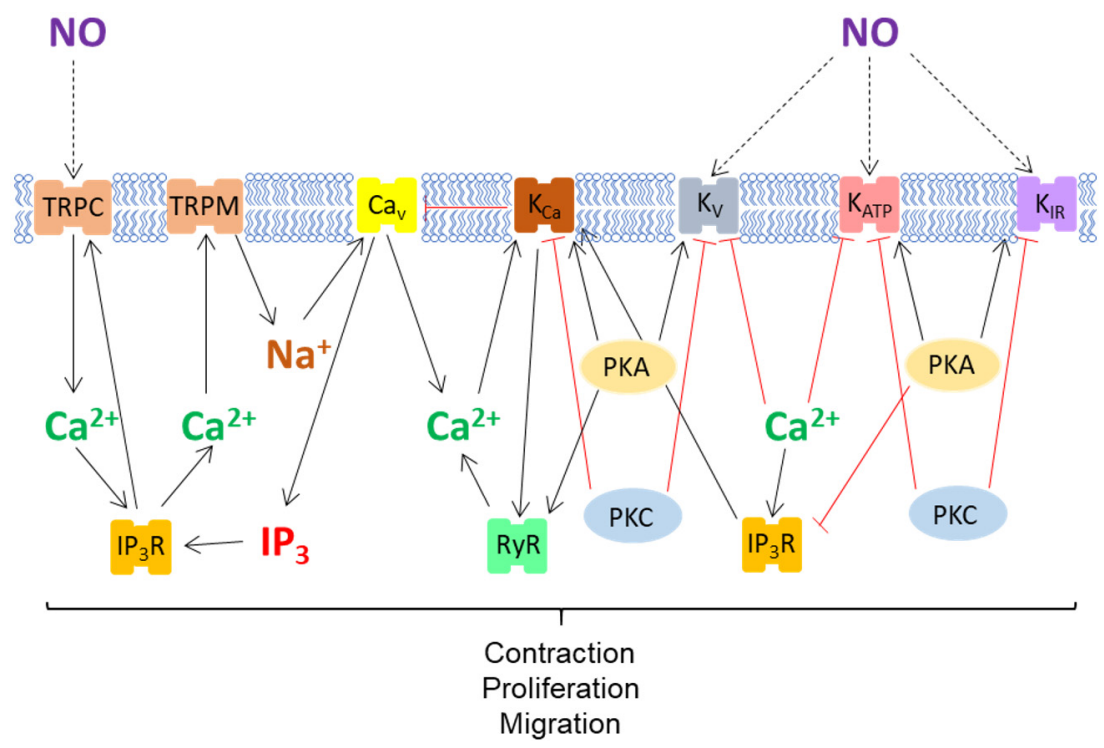

Figure 2. Ion channel signalling in the microvasculature. Regulation of SMC contractility is dependent upon calcium signalling. Microvascular SMC express multiple ion channel subtypes that can influence the level of $\mathrm{Ca}^{2+}$ within the cell, and there is a complex interplay and balance between the channel sub-types. The balance of this signalling dictates whether the cell undergoes contraction/relaxation, proliferation or migration. Black arrow: stimulatory. Red arrow: inhibitory. Dashed arrow: indirect. $\mathrm{K}_{\mathrm{Ca}}$ : Calciumactivated potassium channel; $\mathrm{Ca}_{\mathrm{V}}$ : voltage-gated calcium channel; $\mathrm{IP}_{3}$ : inositol triphosphate; $\mathrm{IP}_{3} \mathrm{R}$ : inositol triphosphate receptor; $\mathrm{K}_{\mathrm{ATP}}$ : ATP-activated potassium channel; $K_{\mathbb{I R}}$ : inwardly-rectifying potassium channel; $K_{\mathrm{V}}$ : voltage-gated potassium channel; NO: nitric oxide; PKA: protein kinase A; PKC: protein kinase C; RyR: ryanodine receptor; TRPC: transient receptor potential C; TRPM: transient receptor potential M.

directly leads to hyperpolarization of neighbouring microvascular SMC via gap junctions, reducing intracellular $\mathrm{Ca}^{2+}$ levels and causing vasorelaxation to increase myocardial blood flow. Whether gap junctions are inhibited in CMD in microvascular SMC has yet to be determined; however, gap junctions between cardiomyocytes and endothelial cells are depleted in CMD in a diabetes setting ${ }^{[34]}$. It is possible that a similar depletion occurs with SMC in CMD, leading to defects in vasorelaxation.

\section{Proliferation and migration}

Early studies into CMD identified SMC hypertrophy in coronary microvessels, with an abundance of contractile machinery. This, in combination with a thickened basement membrane and endothelial cell proliferation, resulted in marked reduction in lumenal space ${ }^{[35]}$. In contrast to this apparent acquisition of a hypercontractile differentiated SMC phenotype, later studies have identified increased coronary microvascular SMC proliferation in CMD patients which is indicative of a dedifferentiated, synthetic phenotype ${ }^{[36]}$. It is possible that in CMD, SMC adopt a "mixed" phenotype that has features of both contractile and synthetic cells. This is not without precedent, as a similarly mixed phenotype has been observed in macrovascular saphenous vein SMC from patients with T2DM, whereby they exhibit a combination of differentiated (increased expression of $\alpha$-SMA, low proliferative rate) and dedifferentiated (rhomboid morphology, disorganized cytoskeleton) features ${ }^{[26,37,38]}$.

Studies in hypothyroid rats have revealed that treatment with triiodothyronine (T3) induced rapid microvascular SMC remodelling through strengthening the contractile phenotype and switching the expression of angiopoietins to favour Angpt 1 over Angpt $2^{[39]}$. This would promote and stabilise microvascular angiogenesis ${ }^{[40]}$ and could help to ameliorate the effects of CMD. Given that hypothyroidism is more common in women ${ }^{[41]}$, this may be one of the underlying mechanisms contributing to CMD. Indeed, even subclinical hypothyroidism has been associated with impaired coronary microvascular 
function $^{[42]}$. Few studies have examined the impact of T3 on coronary artery SMC; however, it is reported to prevent calcification ${ }^{[13]}$ and increase vasorelaxation in rodent coronary arteries ${ }^{[43]}$.

\section{EFFECT OF PREDISPOSING CONDITIONS ON SMC FUNCTION}

There are a number of conditions that can predispose individuals to develop both CMD and CAD. These include medical conditions including diabetes and hypertension, and lifestyle choices such as smoking. However, given that $\mathrm{CMD}$ is more prevalent in young women and $\mathrm{CAD}$ is more prevalent in middle-aged men, it may be that these predisposing conditions have differential effects on coronary micro- and macrovascular SMC.

\section{Diabetes and obesity}

Obesity predisposes individuals to the development of metabolic syndrome and overt T2DM. In a porcine model of metabolic syndrome, microvascular coronary arterioles exhibit hyper-contractile responses via activation of phospholipase A (PLA). Although the authors did not examine whether the increased expression of PLA was in the endothelial cells or SMC, the fact that coronary microvascular SMC were hypercontractile remains ${ }^{[44]}$. In keeping with obesity being a precursor to diabetes and cardiovascular dysfunction, studies in rodents have shown that the coronary microvasculature initially enhances its responses to vasodilators such as $\mathrm{NO}$ by increasing $\mathrm{BK}_{\mathrm{Ca}}$ channel activity and/or sensitivity as an adaptive mechanism to maintain cardiac perfusion ${ }^{[45]}$. In contrast, reduced expression of $\mathrm{K}_{\mathrm{V}}$ and parallel increased expression of $\mathrm{Ca}_{\mathrm{V}} 1.2$ result in elevated intracellular $\mathrm{Ca}^{2+}$ levels and hypercontractility in a swine model of obesity $^{[46]}$. Thus, it is very important to assess the experimental model that is being used to investigate the functional landscape of ion channels in microvascular SMC.

There is a large body of work examining the effect of T2DM on SMC phenotype and function across multiple vascular beds. The structure of small coronary resistance vessels is not affected by the presence of T2DM, with no obvious gross changes at the tissue level ${ }^{[47]}$. There are, however, changes apparent with T2DM with regards to microvascular SMC function. In a cell culture model, coronary microvascular SMC from T2DM patients had reduced stiffness, yet could generate a higher contractile force ${ }^{[27]}$. It is possible that this may explain how T2DM contributes to CMD by increasing the strength of microvascular vasospasm.

At the molecular level, T2DM causes changes in ion channel expression and activity that favour contraction over relaxation. Recent studies have identified that the expression and sensitivity of $\mathrm{BK}_{\mathrm{Ca}}$ channels, and resultant SMC vasodilation are reduced in human coronary arteriolar SMC in T2DM patients ${ }^{[48]}$. Furthermore, a Yucatan swine model of diabetes has revealed impaired $\mathrm{K}^{+}$currents and reduced $\mathrm{Ca}^{2+}$ sparks in the coronary microcirculation ${ }^{[29]}$, strengthening the concept that diabetes is associated with decreased $\mathrm{BK}_{\mathrm{Ca}}$ expression and function and dysregulation of SMC contractility. This appears to be specific to $\mathrm{K}^{+}$ channels as T2DM has no effect on the $\mathrm{Na}^{2+} / \mathrm{K}^{+}$ATPase pump ${ }^{[31]}$. Altered $\mathrm{K}_{\mathrm{IR}}$ functionality in diabetes is complicated by the fact that activity is either unaffected or reduced dependent on the environmental factors that are stimulating the channel ${ }^{[3,49]}$. Furthermore, coronary microcirculation SMC from T2DM patients switch expression of integrins from the 1 subunit to 3 which affects their adhesion to components of the extracellular matrix ${ }^{[27]}$. Endothelial arteriogenesis is dependent on the $\beta 1$ integrin subunit ${ }^{[50]}$, so the transition to $\beta 3$ in microvascular cells in diabetes could conceivably contribute to impaired collateral formation and cardiac ischaemia.

In contrast to the absence of structural changes in microvessels in $\mathrm{T} 2 \mathrm{DM}$, the coronary arteries of these patients demonstrate gross structural changes, namely, they are narrower than those from patients without diabetes. This is even in the absence of atherosclerotic lesions ${ }^{[51]}$ (which are known to be more widespread 
and diffuse in T2DM arteries compared to non-diabetes patients ${ }^{[52]}$ ) and is due to excessive SMC proliferation and migration into the intimal space. Hyperglycaemia bestows protection from apoptosis and triggers the mitogenic ERK p42/44 MAPK pathway ${ }^{[53]}$. This demonstrates the acquisition of a dedifferentiated, synthetic phenotype in macrovascular SMC in diabetes, as opposed to the differentiated contractile phenotype observed in the microvasculature. The molecular changes underpinning why diabetes can affect the phenotype of SMC in such diverse ways, potentially even within the same patient, are not fully understood.

Interestingly, the impairment of $\mathrm{BK}_{\mathrm{Ca}}$ channel expression appears ubiquitous across vascular beds with T2DM, with reduced expression and function being reported in coronary artery SMC from rodent model $s^{[54]}$ and human coronary artery SMC cultured in the presence of high glucose concentration ${ }^{[55]}$. However, the influence of diabetes on other $\mathrm{K}^{+}$mediators such as the $\mathrm{Na}^{+} / \mathrm{K}^{+}$ATPase pump and $\mathrm{K}_{\mathrm{IR}}$ channels within coronary arteries has not been examined. Evidence from diabetic aortic SMC suggests that the Kir subunits of the channel are not affected by diabetes, yet expression of the SUR2B subunit is markedly inhibited ${ }^{[56]}$. Unfortunately, the influence of diabetes and/or hyperglycaemia on $\mathrm{Na}^{+} / \mathrm{K}^{+}$ATPase activity varies according to species and vascular bed ${ }^{[57-59]}$, thus extrapolating a hypothesis on whether this pump is affected in coronary artery SMC is impossible. In terms of proliferation and adhesion to the extracellular matrix, recent studies have found marked reductions in the development of atherosclerosis in a diabetic porcine model when the animals are treated with an integrin $\alpha_{\mathrm{v}} \beta 3$ blocking antibody. Here, the authors suggest that the atheroprotective mechanism of action of the antibody is via blocking the proproliferative influence of $\alpha_{\mathrm{V}} \beta 3^{[60]}$.

Type 1 diabetes (T1DM) accounts for up to $8 \%$ of all diagnosed diabetes cases (www.diabetes.org.uk). It is associated with microvascular dysfunction contributing to diabetes-related cardiomyopathy, where the myocardium becomes fibrotic and there is a reduction in both microvascular endothelial cell and SMC number. What causes this loss of cells is unclear - is it a result of apoptosis, necrosis or proliferative defects? However, in vivo models have shown that application of SMC with endothelial progenitor cells to the myocardium of T1DM rodents is sufficient to at least partially reverse the cardiomyopathy ${ }^{[6]]}$. Similarly to T2DM, T1DM is associated with a reduction in $\mathrm{BK}_{\mathrm{Ca}}$ channel expression and function in the coronary macrovasculature ${ }^{[62]}$, and an increase in adenosine $\mathrm{A}_{2 \mathrm{~A}}$ receptor expression ${ }^{[63]}$. Interestingly, this receptor is associated with a reduction in neointimal hyperplasia and could conceivably contribute to coronary artery SMC being maintained in a contractile phenotype ${ }^{[64]}$. However, $A_{2 A}$ receptors activate both $K_{V}$ and $K_{A T P}$ channels ${ }^{[6]]}$, and these potassium channels promote vasorelaxation (reviewed $\mathrm{in}^{[6]}$ ). The ultimate phenotypic change observed in T1DM coronary vessels is therefore likely a cumulative response to the delicate balance between signalling pathways that are activated in each SMC.

\section{Hypertension}

The influence of essential hypertension on microvascular structure is contentious. Whilst some studies have demonstrated no effect of hypertension on the structure of small coronary resistance vessels ${ }^{[47]}$, others have shown that hypertension increases arteriolar wall thickening through hyaline arteriosclerosis ${ }^{[67]}$. This discrepancy may be due to the different models used - whilst Chen et al ${ }^{[67]}$ performed their experiments on hypertensive rabbits, Lynch et al. ${ }^{[47]}$ used human coronary arterioles for their work. Furthermore, human coronary resistance microvessels were stiffer than their normotensive counterparts ${ }^{[4]}$, and, in a mini-pig model, exhibited impaired vasodilation to adenosine independently of nitric oxide inhibition ${ }^{[68]}$. These functional alterations could conceivably directly contribute to CMD by reducing vasodilation and increasing vasoconstriction and/or spasm. 
Hypertension is intimately linked with the RhoA-ROCK signalling axis (reviewed in ${ }^{[69]}$ ). Information regarding RhoA activity in coronary microvascular SMC, particularly in hypertension, is lacking. However, RhoA is known to be increased in pulmonary microvascular SMC during the development of pulmonary hypertension ${ }^{[70]}$, so it is probable that RhoA is elevated in coronary microvascular SMC. GRAF3 is a negative regulator of RhoA activity, and SNPs resulting in reduced GRAF3 expression are common in hypertensive patients. This results in elevated RhoA activity and contractile gene expression in human coronary artery $\mathrm{SMC}^{[71]}$. Indeed, treatment of patients suffering coronary artery spasm with fasudil, a Rho kinase inhibitor, improves vasodilation and ameliorates chest pain ${ }^{[72]}$, confirming the critical role that the RhoA-Rho kinase pathway plays in both micro- and macro-vascular cardiac disease.

Hayenga et al. ${ }^{[68]}$ conducted an elegant study on hypertensive mini-pigs that revealed that hypertension did not induce global changes in macrovascular structure. Specifically, cerebral arteries had no discernible structural changes after 8 weeks of hypertension. However, both coronary arteries and the aorta exhibited increased wall thickening as soon as 2 weeks after the introduction to hypertension and this was mirrored by a parallel increase in the number of medial cells present. This suggests an increase in SMC proliferation but interestingly, the expression of $\alpha$-SMA was also increased with hypertension ${ }^{[68]}$. It is therefore possible that, in hypertension, coronary arterial SMC adopt a mixed phenotype which, in combination with the mixed SMC phenotypes present in CAD, will make pharmaceutical intervention problematic.

\section{Smoking}

Smoking is known to predispose individuals to a plethora of cardiovascular pathologies including CMD and CAD. A very recent study has demonstrated that exposure to nicotine during pregnancy and early life conveys an increased risk of vascular dysfunction in adulthood. This is through an epigenetic mechanism whereby early nicotine exposure leads to persistent up-regulation of microRNA-181a and consistent, prolonged down-regulation of its target, $\mathrm{BK}_{\mathrm{Ca}}$, in coronary vessel ${ }^{[73]}$, which could contribute to both the aberrant vasorelaxation observed in CMD and the dysfunctional SMC phenotype in CAD.

Exposure of human coronary artery SMC to cigarette smoke in vitro up-regulates the expression of ADAMTS $7^{[74]}$. This protein is involved in degradation of the extracellular matrix and is associated with characteristics of vulnerable plaques including chest pain, low SMC content and enhanced lipid accumulation $^{[75]}$, and with SMC de-differentiation ${ }^{[7]]}$. The expression of ADMATS7 in microvascular SMC has not yet been assessed. However, given that ADAMTS7 is associated with dedifferentiation and migration, one may hypothesise it would be reduced in hypercontractile CMD. Whether cigarette smoking modulates this remains to be seen.

In vivo, exposure to nicotine particles increases the expression of endothelin (ET-1) A and B receptors via ERK and the pro-inflammatory $\mathrm{NF}_{\kappa} \mathrm{B}$ pathway, leading to enhanced coronary artery vasoconstriction ${ }^{[77,78]}$. Interestingly, the effect of ET-1 on coronary vessels is dependent on vessel size - in a canine model, ET-1 induced vasoconstriction of the coronary arteries but a dilation of the coronary arterioles ${ }^{[79]}$. The underlying molecular mechanisms leading to this are unclear, but are likely due to alterations in the expression of ET-1 $\mathrm{A}$ and $\mathrm{B}$ receptors and signalling intermediaries (such as RhoA-Rho kinase ${ }^{[80]}$ ) between the macro- and micro-vascular SMC.

One of the most intriguing questions surrounding CMD is why it is more prevalent in females. Dinardo et al. ${ }^{[81]}$ (2015) examined macrovascular SMC from the internal thoracic artery, and discovered the female gender and smoking were both independently associated with increased SMC stiffness. Enhanced SMC stiffness would contribute to CMD if it was evident in the coronary microcirculation. However, it 
would not necessarily explain why women are less likely to develop CAD.

It is clear from the information presented above that predisposing conditions can have diverse effects on SMC phenotype that can differ across the micro- and macro-vessels [Table 1]. It is likely that it is a cumulative effect of multiple competing molecular triggers from different co-morbidities that define the eventual SMC phenotype in CMD and CAD.

\section{CONCLUSION}

SMC are the principal cell type of the vascular wall. They are highly plastic and can respond to different cues - both physiological and pathophysiological - to alter their phenotype and behaviour. Whilst differentiated, contractile SMC are prevalent in healthy vessels, CMD is characterized by a hyper-contractile phenotype that results in microvascular spasm, impaired vasorelaxation and consequently chest pain. Many factors predispose individuals to developing CMD; these include gender, age, co-morbidities such as diabetes and high blood pressure, and lifestyle choices such as smoking.

Given the key role that SMC play in the regulation of vascular tone, it is surprising that so few mechanistic studies have been performed on this cell type, and coronary microvascular SMC remain an underdeveloped area of research. An examination of the molecular changes in microvascular SMC with predisposing conditions is still in its infancy. Altered molecular and phenotypic signatures in coronary artery SMC have received much greater recognition, yet it is clear that microvascular and macrovascular SMC can respond differently to the same challenges (for example, vasorelaxation or vasoconstriction in response to ET-1). This review has highlighted a number of knowledge gaps in the literature that are worthy of further study:

1. What are the phenotypic differences between microvascular and macrovascular SMC from the same individual, and how are the molecular signatures underpinning this affected by age and gender?

2. How does the ion channel landscape change in human coronary microvascular SMC during the development of CMD?

3. SMC defects are evident in CMD, but there remain species- and vascular bed-specific alterations in protein expression and cell function. How can we generate a model of SMC that specifically examines human CMD, without invasive cardiac biopsies?

4. A reduction in $\mathrm{BK}_{\mathrm{Ca}}$ expression and/or activity appears to be a ubiquitous feature of a number of disorders that predispose an individual to $\mathrm{CMD}$. Can we design therapeutics that restore $\mathrm{BK}_{\mathrm{Ca}}$ in these circumstances to ameliorate CMD?

In summary, a comprehensive examination of SMC phenotypic differences between the coronary microvasculature and the coronary arteries may help to identify new therapeutic targets for CMD that would be amenable to manipulation to restore SMC functionality particularly within these tiny, yet crucially important, vessels. 
Table 1. SMC phenotype in response to different predisposing conditions. Hypertension, obesity, smoking and diabetes all predispose individuals to developing CMD and/or CAD through changing molecular expression pattern in microvascular or macrovascular SMC

\begin{tabular}{|c|c|c|c|}
\hline $\begin{array}{l}\text { Predisposing } \\
\text { condition }\end{array}$ & CMD SMC phenotype & CAD SMC phenotype & Ref. \\
\hline Hypertension & $\begin{array}{l}\text { Pro-contractile (differentiated) } \\
\uparrow \text { RhoA } \\
? \alpha-S M A\end{array}$ & $\begin{array}{l}\text { Mixed phenotype (both de- } \\
\text { /differentiated) } \\
\uparrow R h \circ A \\
\uparrow \alpha-S M A\end{array}$ & {$[71-73]$} \\
\hline Obesity & $\begin{array}{l}\text { Mixed phenotype (both de- } \\
\text { /differentiated) } \\
\uparrow P L A \\
\uparrow B K_{C a} \\
\downarrow K_{V} \\
\uparrow C a_{V} 1.2\end{array}$ & $\begin{array}{l}\text { Unknown phenotype } \\
\text { Studies yet to be completed }\end{array}$ & [45-47] \\
\hline Smoking & $\begin{array}{l}\text { Anti-contractile (dedifferentiated) } \\
\downarrow \text { BK }_{C \text { a }} \text { expression } \\
\text { ? ADAMTS7 } \\
\downarrow \text { ET-1 vasoconstriction }\end{array}$ & $\begin{array}{l}\text { Mixed phenotype (both de- } \\
/ \text { differentiated) } \\
\downarrow \text { BK } \text { Ca }_{\text {a }} \text { expression } \\
\uparrow \text { ADAMTS7 } \\
\uparrow \text { ET- } 1 \text { vasoconstriction }\end{array}$ & {$[74-75,78-80]$} \\
\hline Type 1 diabetes mellitus & $\begin{array}{l}\text { Synthetic (dedifferentiated) } \\
\uparrow \text { Fibrosis } \\
\underline{\text { ? lon channel expression }}\end{array}$ & $\begin{array}{l}\text { Mixed phenotype (both de- } \\
\text { /differentiated) } \\
\downarrow B K_{C a} \\
\uparrow K_{V} \\
\uparrow K_{\text {ATP }} \\
\uparrow A_{2 A} \text { receptor }\end{array}$ & {$[62-64,66]$} \\
\hline Type 2 diabetes mellitus & $\begin{array}{l}\text { Pro-contractile (differentiated) } \\
\downarrow \mathrm{BK}_{\mathrm{C}_{2}} \text { expression } \\
\leftrightarrow \mathrm{Na}^{+} / \mathrm{K}^{+} \text {expression } \\
\leftrightarrow \mathrm{K}_{\mathrm{IR}} \text { expression } \\
\uparrow \text { Integrin } \beta 3\end{array}$ & $\begin{array}{l}\text { Pro-proliferative (de-differentiated) } \\
\downarrow \mathrm{BK}_{\mathrm{G}_{\nexists}} \text { expression } \\
? \mathrm{Na}^{2} / \mathrm{K}^{+} \text {expression } \\
? / \downarrow \mathrm{K}_{\mathrm{IR}} \text { expression } \\
\uparrow \mid \text { Integrin } \beta 3\end{array}$ & {$[28,32,49-50,54-55,57-61]$} \\
\hline
\end{tabular}

CMD: Coronary microvascular dysfunction; CAD: coronary artery disease; SMC: smooth muscle cell; PLA: phospholipase $\mathrm{A}_{\text {; }} \mathrm{BK}_{\mathrm{Ca}}$ : large conductance calcium-activated potassium channel; $\mathrm{K}_{\mathrm{V}}$ : voltage-gated potassium channel; $\mathrm{Ca}_{\mathrm{V}}$ 1.2: voltage-gated calcium channel 1.2; $\mathrm{K}_{\mathrm{IR}}$ : inwardly rectifying calcium channel; $\alpha$-SMA: alpha smooth muscle actin; ADAMTS7: a disentegrin and metalloproteinase with thrombospondin motifs 7; ET-1: endothelin 1; $K_{\text {ATP: }}$ : ATP-activated potassium channel; $A_{2 A}$ : adenosine $2 A$ receptor. $\uparrow$ : increased; $\downarrow$ : reduced; $\leftrightarrow$ : no change; ?: unknown effect in $C M D$ or $C A D$

\section{DECLARATIONS}

\section{Authors' contributions}

The author contributed solely to the article.

Availability of data and materials

Not applicable.

\section{Financial support and sponsorship}

None.

\section{Conflicts of interest}

The author declares that there are no conflicts of interest.

\section{Ethical approval and consent to participate}

Not applicable. 


\section{Consent for publication}

Not applicable.

\section{Copyright}

(c) The Author(s) 2021.

\section{REFERENCES}

1. Taqueti VR, Di Carli MF. Coronary microvascular disease pathogenic mechanisms and therapeutic options: JACC state-of-the-art review. J Am Coll Cardiol 2018;72:2625-41. DOI PubMed PMC

2. Vancheri F, Longo G, Vancheri S, Henein M. Coronary microvascular dysfunction. J Clin Med 2020;9:2880. DOI PubMed PMC

3. Corcoran D, Young R, Adlam D, et al. Coronary microvascular dysfunction in patients with stable coronary artery disease: The CEMARC 2 coronary physiology sub-study. Int J Cardiol 2018;266:7-14. DOI PubMed PMC

4. Izzo P, Macchi A, De Gennaro L, Gaglione A, Di Biase M, Brunetti ND. Recurrent angina after coronary angioplasty: mechanisms, diagnostic and therapeutic options. Eur Heart J Acute Cardiovasc Care 2012;1:158-69. DOI PubMed PMC

5. D'Amario D, Migliaro S, Borovac JA, et al. Microvascular dysfunction in heart failure with preserved ejection fraction. Front Physiol 2019;10:1347. DOI PubMed PMC

6. Montone RA, Meucci MC, De Vita A, Lanza GA, Niccoli G. Coronary provocative tests in the catheterization laboratory: Pathophysiological bases, methodological considerations and clinical implications. Atherosclerosis 2020;318:14-21. DOI PubMed

7. Geraghty L, Figtree GA, Schutte AE, Patel S, Woodward M, Arnott C. Cardiovascular disease in women: from pathophysiology to novel and emerging risk factors. Heart Lung Circ 2021;30:9-17. DOI PubMed

8. Raut BK, Patil VN, Cherian G. Coronary artery dimensions in normal Indians. Indian Heart J 2017;69:512-4. DOI PubMed PMC

9. Goodwill AG, Dick GM, Kiel AM, Tune JD. Regulation of coronary blood flow. Compr Physiol 2017;7:321-82. DOI PubMed PMC

10. Kumar A, D'Souza SS, Moskvin OV, et al. Specification and diversification of pericytes and smooth muscle cells from mesenchymoangioblasts. Cell Rep 2017;19:1902-16. DOI PubMed PMC

11. Owens GK, Kumar MS, Wamhoff BR. Molecular regulation of vascular smooth muscle cell differentiation in development and disease. Physiol Rev 2004;84:767-801. DOI PubMed

12. Porter KE, Riches K. Vascular smooth muscle as a target for novel therapeutics. Curr Diab Rep 2015;15:72. DOI PubMed

13. Lee SJ, Lee IK, Jeon JH. Vascular calcification-new insights into its mechanism. Int J Mol Sci 2020;21:2685. DOI PubMed PMC

14. Bennett MR, Sinha S, Owens GK. Vascular smooth muscle cells in atherosclerosis. Circ Res 2016;118:692-702. DOI PubMed PMC

15. Fazal L, Azibani F, Vodovar N, Cohen Solal A, Delcayre C, Samuel J-L. Effects of biological sex on the pathophysiology of the heart. Br J Pharmacol 2014;171:555-66. DOI PubMed PMC

16. Monk BA, George SJ. The effect of ageing on vascular smooth muscle cell behaviour - a mini-review. Gerontology 2015;61:416-26. DOI PubMed

17. Tykocki NR, Boerman EM, Jackson WF. Smooth muscle ion channels and regulation of vascular tone in resistance arteries and arterioles. Compr Physiol 2017;7:485-581. DOI PubMed PMC

18. Liu Y, Drozdov I, Shroff R, Beltran LE, Shanahan CM. Prelamin A accelerates vascular calcification via activation of the DNA damage response and senescence-associated secretory phenotype in vascular smooth muscle cells. Circ Res 2013;112:e99-109. DOI PubMed

19. Thompson AM, Wagner R, Rzucidlo EM. Age-related loss of SirT1 expression results in dysregulated human vascular smooth muscle cell function. Am J Physiol Heart Circ Physiol 2014;307:H533-41. DOI PubMed

20. Schutzer WE, Reed JF, Mader SL. Decline in caveolin-1 expression and scaffolding of G protein receptor kinase-2 with age in Fischer 344 aortic vascular smooth muscle. Am J Physiol Heart Circ Physiol 2005;288:H2457-64. DOI PubMed

21. DuPont JJ, Kim SK, Kenney RM, Jaffe IZ. Sex differences in the time course and mechanisms of vascular and cardiac aging in mice: role of the smooth muscle cell mineralocorticoid receptor. Am J Physiol Heart Circ Physiol 2021;320:H169-80. DOI PubMed PMC

22. Climie RE, van Sloten TT, Bruno RM, et al. Macrovasculature and microvasculature at the crossroads between type 2 diabetes mellitus and hypertension. Hypertension 2019;73:1138-49. DOI PubMed

23. Bai H, McCaig CD, Forrester JV, Zhao M. DC electric fields induce distinct preangiogenic responses in microvascular and macrovascular cells. Arterioscler Thromb Vasc Biol 2004;24:1234-9. DOI PubMed

24. Gräfe M, Auch-Schwelk W, Hertel H, et al. Human cardiac microvascular and macrovascular endothelial cells respond differently to oxidatively modified LDL. Atherosclerosis 1998;137:87-95. DOI PubMed

25. Kelly JJ, Moore TM, Babal P, Diwan AH, Stevens T, Thompson WJ. Pulmonary microvascular and macrovascular endothelial cells: differential regulation of Ca2+ and permeability. Am J Physiol 1998;274:L810-9. DOI PubMed

26. Riches K, Warburton P, O'Regan DJ, Turner NA, Porter KE. Type 2 diabetes impairs venous, but not arterial smooth muscle cell function: possible role of differential RhoA activity. Cardiovasc Revasc Med 2014;15:141-8. DOI PubMed

27. McCallinhart PE, Cho Y, Sun Z, Ghadiali S, Meininger GA, Trask AJ. Reduced stiffness and augmented traction force in type 2 diabetic coronary microvascular smooth muscle. Am J Physiol Heart Circ Physiol 2020;318:H1410-9. DOI PubMed PMC

28. Sulgin AA, Sidorova TN, Sidorov VY. Growth and characterization of a tissue-engineered construct from human coronary artery smooth muscle cells. Biulleten Sib Meditsiny 2020;19:85-95. DOI PubMed PMC

29. Mokelke EA, Dietz NJ, Eckman DM, Nelson MT, Sturek M. Diabetic dyslipidemia and exercise affect coronary tone and differential 
regulation of conduit and microvessel K+ current. Am J Physiol Heart Circ Physiol 2005;288:H1233-41. DOI PubMed

30. Bychkov R, Gollasch M, Ried C, Luft FC, Haller H. Regulation of spontaneous transient outward potassium currents in human coronary arteries. Circulation 1997;95:503-10. DOI PubMed

31. Miura H, Toyama K, Pratt PF, Gutterman DD. Cigarette smoking impairs Na+-K+-ATPase activity in the human coronary microcirculation. Am J Physiol Heart Circ Physiol 2011;300:H109-17. DOI PubMed PMC

32. Miura H, Liu Y, Gutterman DD. Human coronary arteriolar dilation to bradykinin depends on membrane hyperpolarization: contribution of nitric oxide and Ca2+-activated K+ channels. Circulation 1999;99:3132-8. DOI PubMed

33. Zhao G, Joca HC, Nelson MT, Lederer WJ. ATP- and voltage-dependent electro-metabolic signaling regulates blood flow in heart. Proc Natl Acad Sci U S A 2020;117:7461-70. DOI PubMed PMC

34. Cabrera JTO, Si R, Makino A. Gap junction intercellular communication and coronary microvascular disease in Type 2 diabetes. FASEB 2020;34:1. DOI

35. Osamichi S, Kouji K, Yoshimaro I, et al. Myocardial glucose metabolism assessed by positron emission tomography and the histopathologic findings of microvessels in syndrome X. Circ J 2004;68:220-6. DOI PubMed

36. Lindemann H, Petrovic I, Hill S, et al. Biopsy-confirmed endothelial cell activation in patients with coronary microvascular dysfunction. Coron Artery Dis 2018;29:216-22. DOI PubMed

37. Madi HA, Riches K, Warburton P, O'Regan DJ, Turner NA, Porter KE. Inherent differences in morphology, proliferation, and migration in saphenous vein smooth muscle cells cultured from nondiabetic and Type 2 diabetic patients. Am J Physiol Cell Physiol 2009;297:C1307-17. DOI PubMed

38. Riches K, Alshanwani AR, Warburton P, et al. Elevated expression levels of miR-143/5 in saphenous vein smooth muscle cells from patients with Type 2 diabetes drive persistent changes in phenotype and function. J Mol Cell Cardiol 2014;74:240-50. DOI PubMed PMC

39. Savinova OV, Liu Y, Aasen GA, et al. Thyroid hormone promotes remodeling of coronary resistance vessels. PLoS One 2011;6:e25054. DOI PubMed PMC

40. Lilly B. We have contact: endothelial cell-smooth muscle cell interactions. Physiology (Bethesda) 2014;29:234-41. DOI PubMed

41. Carlé A, Pedersen IB, Knudsen N, Perrild H, Ovesen L, Laurberg P. Gender differences in symptoms of hypothyroidism: a populationbased DanThyr study. Clin Endocrinol (Oxf) 2015;83:717-25. DOI PubMed

42. Traub-Weidinger T, Graf S, Beheshti M, et al. Coronary vasoreactivity in subjects with thyroid autoimmunity and subclinical hypothyroidism before and after supplementation with thyroxine. Thyroid 2012;22:245-51. DOI PubMed

43. Yoneda K, Takasu N, Higa S, et al. Direct effects of thyroid hormones on rat coronary artery: nongenomic effects of triiodothyronine and thyroxine. Thyroid 1998;8:609-13. DOI PubMed

44. Lawandy I, Liu Y, Shi G, et al. Increased coronary arteriolar contraction to serotonin in juvenile pigs with metabolic syndrome. Mol Cell Biochem 2019;461:57-64. DOI PubMed PMC

45. Climent B, Sánchez A, Moreno L, et al. Underlying mechanisms preserving coronary basal tone and NO-mediated relaxation in obesity: Involvement of $\beta 1$ subunit-mediated upregulation of BK(Ca) channels. Atherosclerosis 2017;263:227-36. DOI PubMed

46. Berwick ZC, Dick GM, O'Leary HA, et al. Contribution of electromechanical coupling between Kv and Ca v1.2 channels to coronary dysfunction in obesity. Basic Res Cardiol 2013;108:370. DOI PubMed PMC

47. Lynch FM, Izzard AS, Austin C, et al. Effects of diabetes and hypertension on structure and distensibilty of human small coronary arteries. J Hypertens 2012;30:384-9. DOI PubMed

48. Lu T, Chai Q, Jiao G, et al. Downregulation of BK channel function and protein expression in coronary arteriolar smooth muscle cells of type 2 diabetic patients. Cardiovasc Res 2019;115:145-53. DOI PubMed PMC

49. Miura H, Wachtel RE, Loberiza FR Jr, et al. Diabetes mellitus impairs vasodilation to hypoxia in human coronary arterioles: reduced activity of ATP-sensitive potassium channels. Circ Res 2003;92:151-8. DOI PubMed

50. Henning C, Branopolski A, Follert P, et al. Endothelial $\beta 1$ integrin-mediated adaptation to myocardial ischemia. Thromb Haemost 2021. DOI PubMed

51. Mosseri M, Nahir M, Rozenman Y, et al. Diffuse narrowing of coronary arteries in diabetic patients: the earliest phase of coronary artery disease. Cardiology 1998;89:103-10. DOI PubMed

52. Munnur RK, Nerlekar N, Wong DT. Imaging of coronary atherosclerosis in various susceptible groups. Cardiovasc Diagn Ther 2016;6:382-95. DOI PubMed PMC

53. Sakuma H, Yamamoto M, Okumura M, Kojima T, Maruyama T, Yasuda K. High glucose inhibits apoptosis in human coronary artery smooth muscle cells by increasing bcl-xL and bfl-1/A1. Am J Physiol Cell Physiol 2002;283:C422-8. DOI PubMed

54. Lu T, Ye D, He T, Wang XL, Wang HL, Lee HC. Impaired Ca2+-dependent activation of large-conductance Ca2+-activated K+ channels in the coronary artery smooth muscle cells of Zucker Diabetic Fatty rats. Biophys J 2008;95:5165-77. DOI PubMed PMC

55. Yi F, Wang H, Chai Q, Wang X, Shen WK, Willis MS, Lee HC, Lu T. Regulation of large conductance Ca2+-activated K+ (BK) channel $\beta 1$ subunit expression by muscle RING finger protein 1 in diabetic vessels. J Biol Chem 2014;289:10853-64. DOI PubMed PMC

56. Ren Y, Xu X, Wang X. Altered mRNA expression of ATP-sensitive and inward rectifier potassium channel subunits in streptozotocininduced diabetic rat heart and aorta. J Pharmacol Sci 2003;93:478-83. DOI PubMed

57. Gupta S, Chough E, Daley J, et al. Hyperglycemia increases endothelial superoxide that impairs smooth muscle cell Na+-K+-ATPase activity. Am J Physiol Cell Physiol 2002;282:C560-6. DOI PubMed

58. Gupta S, Sussman I, McArthur CS, Tornheim K, Cohen RA, Ruderman NB. Endothelium-dependent inhibition of Na(+)-K+ ATPase activity in rabbit aorta by hyperglycemia. Possible role of endothelium-derived nitric oxide. J Clin Invest 1992;90:727-32. DOI 
PubMed PMC

59. Smith JM, Paulson DJ, Solar SM. Na+/K(+)-ATPase activity in vascular smooth muscle from streptozotocin diabetic rat. Cardiovasc Res 1997;34:137-44. DOI PubMed

60. Maile LA, Busby WH, Xi G, et al. An anti- $\alpha \mathrm{V} \beta 3$ antibody inhibits coronary artery atherosclerosis in diabetic pigs. Atherosclerosis 2017;258:40-50. DOI PubMed

61. Kawamura M, Paulsen MJ, Goldstone AB, et al. Tissue-engineered smooth muscle cell and endothelial progenitor cell bi-level cell sheets prevent progression of cardiac dysfunction, microvascular dysfunction, and interstitial fibrosis in a rodent model of type 1 diabetes-induced cardiomyopathy. Cardiovasc Diabetol 2017;16:142. DOI PubMed PMC

62. Tang X, Qian LL, Wang RX, et al. Regulation of coronary arterial large conductance Ca2+-activated K+ channel protein expression and function by n-3 polyunsaturated fatty acids in diabetic rats. J Vasc Res 2017;54:329-43. DOI PubMed

63. Labazi H, Teng B, Zhou Z, Mustafa SJ. Enhanced A2A adenosine receptor-mediated increase in coronary flow in type I diabetic mice. J Mol Cell Cardiol 2016;90:30-7. DOI PubMed PMC

64. Johnston-Cox HA, Koupenova M, Ravid K. A2 adenosine receptors and vascular pathologies. Arterioscler Thromb Vasc Biol 2012;32:870-8. DOI PubMed PMC

65. Berwick ZC, Payne GA, Lynch B, Dick GM, Sturek M, Tune JD. Contribution of adenosine A(2A) and A(2B) receptors to ischemic coronary dilation: role of K(V) and K(ATP) channels. Microcirculation 2010;17:600-7. DOI PubMed PMC

66. Dogan MF, Yildiz O, Arslan SO, Ulusoy KG. Potassium channels in vascular smooth muscle: a pathophysiological and pharmacological perspective. Fundam Clin Pharmacol 2019;33:504-23. DOI PubMed

67. Chen Y, Waqar AB, Yan H, Wang Y, Liang J, Fan J. Renovascular hypertension aggravates atherosclerosis in cholesterol-fed rabbits. J Vasc Res 2019;56:28-38. DOI PubMed

68. Hayenga HN, Hu JJ, Meyer CA, et al. Differential progressive remodeling of coronary and cerebral arteries and arterioles in an aortic coarctation model of hypertension. Front Physiol 2012;3:420. DOI PubMed PMC

69. Loirand G, Pacaud P. Involvement of Rho GTPases and their regulators in the pathogenesis of hypertension. Small GTPases 2014;5:110. DOI PubMed PMC

70. Zhang Y, Dai L, Wu S, Chen P, Zhao S. Atorvastatin attenuates involvement of RhoA/Rho-kinase pathway and NF- $\mathrm{kB}$ activation in hypoxic pulmonary hypertensive rats. Chin Med J (Engl) 2014;127:869-72. PubMed

71. Bai X, Mangum K, Kakoki M, Smithies O, Mack CP, Taylor JM. GRAF3 serves as a blood volume-sensitive rheostat to control smooth muscle contractility and blood pressure. Small GTPases 2020;11:194-203. DOI PubMed PMC

72. Masumoto A, Mohri M, Shimokawa H, Urakami L, Usui M, Takeshita A. Suppression of coronary artery spasm by the Rho-kinase inhibitor fasudil in patients with vasospastic angina. Circulation 2002;105:1545-7. DOI PubMed

73. Liu B, Hu X, Li Y, et al. Epigenetic down-regulation of BK(Ca) channel by miR-181a contributes to the fetal and neonatal nicotinemediated exaggerated coronary vascular tone in adult life. Int J Cardiol 2019;281:82-9. DOI PubMed PMC

74. Saleheen D, Zhao W, Young R, et al. Loss of cardioprotective effects at the ADAMTS7 locus as a result of gene-smoking interactions. Circulation 2017;135:2336-53. DOI PubMed PMC

75. Bengtsson E, Hultman K, Dunér P, et al. ADAMTS-7 is associated with a high-risk plaque phenotype in human atherosclerosis. Sci Rep 2017;7:3753. DOI PubMed PMC

76. Wang L, Zheng J, Bai X, et al. ADAMTS-7 mediates vascular smooth muscle cell migration and neointima formation in ballooninjured rat arteries. Circ Res 2009;104:688-98. DOI PubMed

77. Huang LH, Zhang PA, He JY, Liu J, Cao YX. DMSO-soluble cigarette smoke particles alter the expression of endothelin B receptor in rat coronary artery. J Vasc Res 2013;50:238-48. DOI PubMed

78. Cao L, Zhang Y, Cao YX, Edvinsson L, Xu CB. Cigarette smoke upregulates rat coronary artery endothelin receptors in vivo. PLoS One 2012;7:e33008. DOI PubMed PMC

79. Lamping KG, Clothier JL, Eastham CL, Marcus ML. Coronary microvascular response to endothelin is dependent on vessel diameter and route of administration. Am J Physiol 1992;263:H703-9. DOI PubMed

80. Tsai SH, Lu G, Xu X, Ren Y, Hein TW, Kuo L. Enhanced endothelin-1/Rho-kinase signalling and coronary microvascular dysfunction in hypertensive myocardial hypertrophy. Cardiovasc Res 2017;113:1329-37. DOI PubMed PMC

81. Dinardo CL, Santos HC, Vaquero AR, et al. Smoking and female sex: independent predictors of human vascular smooth muscle cells stiffening. PLoS One 2015;10:e0145062. DOI PubMed PMC 